Swarthmore College

Works

1984

\title{
The Semantics Of Desire: Changing Models Of Identity From Dickens To Joyce
}

Philip M. Weinstein

Swarthmore College, pweinst1@swarthmore.edu

Follow this and additional works at: https://works.swarthmore.edu/fac-english-lit

Part of the English Language and Literature Commons

Let us know how access to these works benefits you

\section{Recommended Citation}

Philip M. Weinstein. (1984). "The Semantics Of Desire: Changing Models Of Identity From Dickens To Joyce". The Semantics Of Desire: Changing Models Of Identity From Dickens To Joyce. https://works.swarthmore.edu/fac-english-lit/81

This work is brought to you for free by Swarthmore College Libraries' Works. It has been accepted for inclusion in English Literature Faculty Works by an authorized administrator of Works. For more information, please contact myworks@swarthmore.edu. 


\section{Introduction}

If the fool would persist in his folly he would become wise.-Blake, The Marriage of Heaven and Hell

THIS STUDY explores the changing relation between desire and value, as they affect the protagonists' identity, in English novels between 1850 and 1928. I examine the imaginative predilections of two mid-Victorians, two late-Victorians, and two Modernists. Each chapter seeks to identify the novelist's characteristic stance toward desire by interrogating in detail a pair of his novels. ${ }^{1}$ The study moves from narratives of repression and disguise in Dickens and Eliot to narratives of release and celebration in Lawrence and Joyce.

Seen synoptically, my book inquires into the novelistic imagination of freedom. It does so by examining a range of protagonists' capacities to accommodate and turn to creative personal use the givens of nature and culture. To be in a body is to experience desire and to be inscribed in the natural world of space and time. To have a mind is to inherit attitudes toward desire because one is inscribed in the cultural world of sanctions and prohibitions. Since no one creates either his body or his mind, all embodied thinking subjects-all protagonists - achieve their freedom in the measure that they come to terms with these matrical systems of nature and culture. ${ }^{2}$

1 My discussion of Joyce centers on the major novel, Ulysses.

2 I realize that there are other and more spectacular forms of freedom, especially those that involve a risk of one's being in behalf of a chosen ideal. This is the domain of heroism proper. I have chosen to focus on a more obscure (though omnipresent) realm of freedom, that involved in a subject's relation to his inalienable given conditions. 
Allegiance to nature and culture is involuntary. The character of the allegiance alters, however, and that alteration is the subject of my book. At its most schematic, the argument goes like this: the mid-Victorians privilege culture; they imagine the protagonist becoming himself-achieving freedom-by subordinating the givens of his natural body. The Modernists, by contrast, privilege nature; they envisage the protagonist's freedom and self-enactment in his capacity to affirm desire and to resist, ignore, or simply endure his culture's injunctions. Freedom is possible in both of these positions. For the novelists who come between mid-Victorian and Modern, however-for Hardy and Conrad-neither culture nor nature is privileged. Both systems are in limbo. The cultural scripts within the protagonist have lost their force but may not be discarded, while his natural propensities wreak havoc with his goals but may not be sanctioned. Hardy and Contrad cannot imagine self-discovery in terms other than self-rupture. Split between nature and culture, their protagonists rarely achieve identity or freedom.

This development has considerable formal consequences. We begin with the mid-Victorian plot of a cohesive protagonist moving through public space and time and, eventually, either achieving the social career that he has personally willed or failing (for carefully documented reasons) to do so. This is the plot of Dickens and Eliot in which an unruly self grows up. His freedom is enacted as his capacity to realize-through his will-the prescriptions of his culture: as Freud would say, to live up to the requirements of his superego. The late-Victorian plot of Hardy and Conrad characteristically accepts these societal terms but cannot make good on them. Tess and Jude, Jim and Nostromo, want to love, work, and succeed exactly as their culture prescribes, but the prescription is becoming chimera-like, beckoning yet unrealizable. Something at the core of the protagonist insists on or cannot evade the sabotage of aspirations.

The novels of Lawrence and Joyce exploit this element of sabotage. Their early Bildungsromane elaborate the acculturation plot in all of its impossibility. Neither writer can imagine the subjective experience of freedom in its terms. Lawrence and Joyce both conceive a protagonistic self in opposition to this model, a 
self that is not performed through the exercise of will, and not interested in a career defined by lengthy apprenticeship to and eventual mastery over culturally approved forms of work. Their great novels formally abandon or parody the plot of social integration. Lawrence imagines identity and freedom elsewhere; Joyce (in Ulysses) reconceives them here, within culture, but in terms that would perplex or scandalize his Victorian predecessors.

I shall argue in Part One that in the fiction of Dickens and Eliot the subject is conceived as transcendentally pure, established prior to cultural or natural constraints. Unlike the rebellious Romantic version of this subject, the transcendental Victorian subject chooses acculturation; he joins up. This orderly conception is of course disseminated by Victorian society; it is one of its foremost conventions. Thoughts and behavior that continue to transgress this normative convention may not be sanctioned in the protagonist; his career unfolds in the form of his gradual, often painful, assimilation of this norm.

Such a career may exact a considerable price, for it insists on a subject fully capable of altruism, discipline, and earnestness: a subject who subordinates his own concerns to those of others, who controls his body's impulses, and whose consciousness is capable of self-knowledge. My study begins at those moments when this subject starts to become unimaginable. That is, those occasions on which Dickens and Eliot are unable to imagine the protagonist fulfilling his prescription because other elements, just glimpsed in the self but somehow exigent, seem to require another denouement. In Dickens and Eliot these are only occasions because their imaginations are usually on good terms with their culture's protagonistic norm. Indeed, they never knowingly violate this norm. The panorama of characters unlike the protagonist usually permits the lateral siphoning off of illicit energies. At times, however, something does go wrong. The writer's imagination, uncoercible, shows signs of apostasy. It apprehends as subjectively desirable a course of actions or cluster of feelings that the dictates of conscience must abjure.

In Hardy and Conrad the cultural allegiances that make up conscience remain in place, but the writer's immediate apprehension of his subject's thoughts, desires, and probable behavior has 
become further thwarted. He cannot imagine the free development of a protagonist in terms that intersect his culture's norms, and he cannot endorse a development that violates those norms. I think of these novels as "tragic encounters" because the incarnate subject is embarked, increasingly, on a career conceived in terms that ensure disaster. His culturally enjoined identity-the sanctions by which he recognizes, orients, and evaluates himself-is losing its purchase on the immediate data of thought and feeling. He finds himself experiencing what he is incapable of accommodating; his culture has led him to propose for himself projects which he has no means of achieving. The scripts of legibility through which the culture licenses its models of identity are becoming for him inapplicable, but he will cancel himself through suicide rather than repudiate those scripts. His creator can imagine no exit from this dilemma.

Lawrence and Joyce begin to demythologize these scripts. Both writers overtly recognize (rather than merely imply) the injurious effects of culturally licensed norms of identity, aspiration, and career. The subject can be imagined as free again, because the relation between the subject and the myriad elements that compose and constrain it has been reconceived. The self no longer yearns to be transcendentally prior to the natural world (its incarnate grounding, the locus of its desires and actual possibilities), nor does it seek a perfect fusion with the cultural world (its ideological grounding, its human inheritance). The narratives that contain these newly conceived subjects are likewise redesigned to accommodate their newfound freedom. No plots of societal career that presuppose shared societal norms, likewise no plots of achieved escape that pre-suppose a transcendental self free of societal traces: in fact, little plot at all, for the freedom of these embodied subjects is largely constituted by their momentby-moment movement in time, essaying (sometimes whimsically, sometimes ecstatically) their conditional possibilities.

ie.

SUCH, in summary form, is the argument of this book. I need now (at the risk of re-inventing the wheel) to identify the literary and philosophical premises that have made the argument possi- 
ble. These premises, everywhere operative though often unstated, cluster about the following terms: freedom, protagonist, plot, subject, self and society, transcendental and contingent, identity, and (above all) imagination.

The question of freedom provides the rationale for this study's focus upon the career of the central figure(s), the protagonist(s), as well as for its considerable attention to the shape of plots. The protagonist is the character through whom the creative writer tends to imagine most intimately the experience of freedom. It is true, of course, that novelists project their sense of inner possibility into the whole of their created canvas-its range of characters, its cluster of plots, its typical movement, its setting, its syntax. But preeminently they convey their own subjective reality (what it feels like to be alive, responsive, and desiring in a world of others) through the creation of protagonists.

Protagonists enact, however, a dual allegiance. If they house their creator's psychic investment, they also testify to the normative stresses of the society within which their creator moves. This crossing of subjective energy and societal constraint defines, for my study, their peculiar interest. Becky Sharpe, for example, accommodates her creator's shrewdest sense of reality, but Thackeray has not treated her as a protagonist: he has not sought to align her energies within the web of her society's norms. Indeed, she may be defined as the power of illicit energies on the other side of the norms. In the Victorian novel the protagonists must move, in good faith, in the daylight of their culture's sanctions, however shaped they may be, simultaneously, by the nocturnal energies of their creator's imagination. (This tension between sanctioned forms of expression and wayward energies seeking release is the recurrent focus of Parts One and Two of this study. In Part Three the tension alters, as the Modernists call into question the sanctioning process itself.)

The range of movements that these protagonists desire to make exists in a dialectic relation to the movements that they are actually empowered to make. The shape of this dialectic is the plot. To discuss the plot is to register the variety of non-subjective elements that affect the career of the protagonists: their capacity for freedom. 
Paradoxically, this opposition-protagonist versus societyis at the same time an equation: protagonist-and-society. The self that desires and the society that restrains are interpenetrative terms. The romantic opposition of self (unscripted, pure) versus society (scripted, maculate, corrupting) is, on scrutiny, untenable-untenable because it assumes that self is transcendentally prior to society. If we reject this metaphysical assumption, we must conclude that "self" and "society" answer to opposed optics on a common spectrum of phenomena, for how could self be constituted if not from the materials - family, school, church, law, customs, etc. - of society? And how could society be conceived apart from its status as a historically descended commonwealth of selves?

The materials are common but the optics are opposed. This simple point has considerable implications. Self can neither vanquish society nor be merged into it: their difference is as inextinguishable as it is incomplete. An entity located in society, in every respect composed of elements common to society, self is nevertheless not society. Or, to put it more precisely, self refers to no entity at all-for entity implies object-but rather to the characteristic mode of relations that an individual as subject sustains with himself and with the social world in which he lives.

For the writer as writer, that mode of subjective relation is imaginative: we arrive thus at one of the governing concepts of this study, imagination. Imagination is the writer's preeminent faculty, a power of perception that has no transcendental status, is at all times conditioned, but is nevertheless unpredictable. It carries the writer's identity for, unlike his conscience, it is not the property of his culture's norms. Not that it is exclusively his own property either, to be shaped at will. "Perception is not whimsical but fatal," says Emerson, and imagination is that ineluctable manner of seeing things that marks the writer's ineluctable identity (156). Operative within consciousness but not coequal with it, shaped through the pressure of conscience by cultural sanctions but equally a mode of responding to and deploying those sanctions, gradually and unconsciously formed over the years, a writer's imagination is his signature. It expresses (with whatever internal fissures) his inclusive way of reading his world. ${ }^{3}$

${ }^{3}$ For a shrewd discussion of how a writer's conflicted psychology creates 
The point is important because it carries the issue of the writer's freedom (and by extension that of his characters). To be conditioned is not to be unfree; to be shaped by societal paradigms is not to be deprived of self. Self is authenticated through the deployment of materials not self-originated. The presence of ineradicable societal traces within a writer's imagination only means that his freedom is constituted by his relation to those traces: by what he does with and through them. The evolving dialectic between a writer's imagination and his given conditions (both inner and outer)-a dialectic as unpredictable as it is unrepeatable-finally is his creative freedom. Meditating on this dialectic, Proust states the case succinctly:

Moreover this reaction of locally procured materials on the genius who utilises them and to whose work their reaction imparts an added freshness, does not make the work any less individual, and whether it be that of an architect, a cabinet-maker or a composer, it reflects no less minutely the most subtle shades of the artist's personality, because he has been compelled to work in the millstone of Senlis or the red sandstone of Strasbourg, has respected the knots peculiar to the ash-tree, has borne in mind, when writing his score, the resources, the limitations, the volume of sound, the possibilities of a flute or alto voice. (I:682)

The authority of individual achievement (and thereby the creator's identity) depends not on the myth of a transcendental subject working within the vacuum of its self-chosen terms and instruments. Rather, Proust indicates, it emerges through the performance of a contingent subject operating under the pressure of innumerable restrictions, and actualizing himself through those restrictions. Such a performative model of identity accommo-

fissures within the writing itself, see the essays Frederick Crews has collected in Out of My System. Crews candidly discusses the appeal and the pitfalls of a psychoanalytic approach to literature. See also Julia Kristeva's Desire in Language: $A$ Semiotic Approach to Literature and Art. Kristeva locates the problematics of language in both the artifice of the sign and instinctual drives that skew any straightforward communication of meaning. Mikhail Bakhtin very suggestively reads Dostoevsky's entire corpus as an interplay of conflicting subjective voices, none subordinated to a single commanding design. 
dates both authors and their protagonists; it underlies in a number of ways the argument of this book.

With respect to authors, the model suggests that their power is inseparable from their receptivity-to the bias of their imagination, to the exigencies of their medium, to the constraints of their culture. The writer's imagination, even as it eludes his wouldbe-sovereign will, records the stresses of his situation. He may truck with his imagination, abuse it, exploit it, but he cannot commandeer its testimony. (The latent quarrel within this faculty between the press of nature and the restraint of culture [between the unconscious and the superego] animates my chapters on Dickens and Eliot. This same quarrel, become overt, animates my chapters on Hardy and Conrad. The attempt to heal the quarrel animates my chapter on Lawrence and Joyce.)

Insofar as the Proustean model accommodates protagonists, it focuses attention less on their intrinsic properties than on their mode of relations with the world they inhabit. Freedom and identity emerge in the subject's transactions, in his capacity, not to create new conditions, but to realize himself by accepting and energizing his given conditions. Throughout, of course, these given conditions are nature and culture, bodily desire and societal constraint. They have been addressed first in terms of my book's argument, next in terms of its premises. They may now be approached in terms of its methodology.

re

The semantics of desire: my title comes from Paul Ricoeur. In the opening pages of his study of Freud, Ricoeur speaks of "the semantics of desire, a semantics that centers around a somewhat nuclear theme: as a man of desires I go forth in disguiselarvatus prodeo" (6-7). A man of desires is opaque-to himself, to others. To be understood, he must be subjected to a hermeneutical scrutiny that will unravel his utterance by locating the kernel of unacknowledged desire that is serving as its orientation. Ricoeur goes on to identify Marx, Nietzsche, and Freud as the three master critics of a school of suspicion that specializes in the art of unmasking. In their work the testimony of subjective consciousness becomes systematically suspect, for consciousness is 
everywhere blind to its own strategic biases. Conditioned by an economic system that dictates his ideology, a libidinal system that controls his erotic choices, and a will to power that predisposes him to the exploitation of others, the mystified subject nevertheless manages to think of himself as transcendentally free, guileless, and self-knowing. "Beginning with [Marx, Nietzsche, and Freud]," Ricoeur writes, "understanding is hermeneutics: henceforward, to seek meaning is no longer to spell out the consciousness of meaning, but to decipher its expressions" (33).

In order to assess properly the subject's hidden conditionality, this study will supplement its literary analysis by drawing (especially in the chapter on Dickens) on Nietzsche and Freud. Both thinkers subvert a nineteenth-century model of the subject as innocent and autonomous. Nietzche seeks to dislodge this model of the subject by exposing the concealed presence of an amoral will to power within its discourse and behavior, while Freud's hermeneutic charts the disowned movement of unresolved (and likewise amoral) sexual energies within the same discourse and behavior. For both thinkers, the subject is essentially unaware of his own motives.

A critical methodology rigidly shaped to the contours of the Freud-Nietzsche model has, however, its limitations. Put simply, such a model is too suspicious; it assumes, programmatically, that consciousness is opaque to all of the subject's deeper intentions. The point is important because Marx, Nietzsche, and Freud-in their common premise of a mystified subject-have served as a point de répère for recent interpretive theory. The shared premise is that an initiated observer with a privileged hermeneutical lens can identify those ideological crossings that the author himself has absorbed but not understood, and which have actively produced his text. ${ }^{4}$ Terry Eagleton writes:

${ }^{4}$ The contemporary makers of this argument are legion. For an excellent overview, see Josue V. Harari's "Critical Factions/Critical Fictions." A handful of representative works that explore or expound this premise include Jonathan Culler's Structuralist Poetics, Paul de Man's Blindness and Insight, Terry Eagleton's Criticism and Ideology, Michel Foucault's Les mots at les choses and L'ordre du discours, Frank Lentricchia's After the New Criticism, and Edward Said's Beginnings. 
Criticism is not a passage from text to reader: its task is not to redouble the text's self-understanding, to collude with its object in a conspiracy of eloquence. Its task is to show the text as it cannot know itself, to manifest those conditions of its making (inscribed in its very letter) about which it is necessarily silent. It is not just that the text knows some things and not others; it is rather that its very self-knowledge is the construction of a self-oblivion. (43)

To an extent I have followed this shrewd (and in its way irresistible) advice: the author begets but does not own his text. Ineradicably stained by ideology himself, how could he fail to produce a text that says more and other things than it knows itself saying? The critic's job is not to cooperate with the text but to expose it. Explain, don't interpret: so runs the current axiom. The stance is deliberately neutral if not hostile. The text must be approached from a standpoint as insistently external to the text's own self-understanding as possible. This argument is buttressed by the sophisticated awareness that no text can be fully entered on its own subjective terms anyway: and if the critic is irremediably outside, let him make a virtue of his foreignness.

At this point the price that a hermeneutics of suspicion pays for its insight comes into view. The subject is transformed into the object. Since it cannot be grasped in its self-understanding, since, moreover, it has no access to its own deepest implications, it must expressly undergo a tactics of alienation. It becomes, in the current critical act, an entity foreign to itself and foreign to its observer. ${ }^{5}$ Insofar as my deepest epistemological conviction is that we understand only those human objects whose inner subjectivity we can imagine, I draw back from this model of the alienated object. It needs to be counter-balanced by a model of the coherent subject.

This counter-model is phenomenological in two respects. It reads the work of art as expression, as a complex imaginative

${ }^{5}$ Roland Barthes' $S / Z$, in its dismantling and reconstruction of an inconspicuous tale by Balzac, is probably the terminus ad quem of this methodological model. Barthes' interest in the tale, and his capacity to find the tale interesting, are remarkable. What is generally missing, however, is Balzac. 


\section{INTRODUCTION}

gesture toward wholeness and self-discovery on the part of the author who created the work. And it proposes, as the task of criticism, the most intimate relation possible to the creative voice at the heart of the work. ${ }^{6}$ This intimacy, like all intimacy, depends upon a critical surrender to the entity being approached. My book seeks, therefore, to approach the self-understanding of the novelistic universe in question, to identify its nodal and enabling assumptions, those creative premises that have generated its characteristic shape and concerns and that intimate what can and cannot be achieved within its contours. I do not claim to have entered the subjective voice of each novelist, and it may be that my attempt to approach that voice is, ultimately, indefensible (because, the Derridean argument runs, there is no voice to be approached). In any event, I remain persuaded that the writer's imagination does shape such a voice, and that deliberately to ignore it amounts to a denaturing of the object under scrutiny.

Edward Said discusses the issue of the writer's command over his own meanings in terms of authority and molestation. Authority refers to the related notions of begetting, continuing, controlling, and possessing that are bound up in the master idea of an empowering creative subject. Molestation refers to the ob-

6 Within the practice of literary criticism, phenomenology means, most generally, those methodologies that seek to locate in a writer's work (indeed in all his utterances) the hidden movement of his subjective consciousness in search of its own wholeness. This search necessarily traverses the entire world of objects within which the subject lives: for the riddle of subjective identity is inscribed precisely in his manifold relations with the objective world. Practitioners I have learned most from are Georges Poulet, Jean-Pierre Richard, and (in their earlier work) Leo Bersani, Geoffrey Hartman, and J. Hillis Miller. See Georges Poulet, Studies in Human Time, The Interior Distance, The Metamorphoses of the Circle; Jean-Pierre Richard, Littírature et sensation; Leo Bersani, Marcel Proust: The Fictions of Life and Ant; Geoffrey $\mathrm{H}$. Hartman, Wordsworth's Poetry: 1787-1814; J. Hillis Miller, Charles Dickens: The World of His Novels; The Disappearance of God: Five Nineteenth-Century Writers; Poets of Reality: Six Twentieth-Century Writers; and Thomas Hardy: Distance and Desire. Sarah Lawall discusses many of these critics and their interpretive models in her Critics of Consciousness. As a philosophical movement, Phenomenology derives from the work of Edmund Husserl. Nonspecialists will find a more accessible presentation of the major premises in Maurice Merleau-Ponty, Paul Ricoeur (Le conflit des interprétations), and Vincent Descombes. 
stacles to authority, "a consciousness of one's duplicity, one's confinement to a fictive, scriptive realm, whether one is a character or a novelist" (84). The terms are necessarily dialectical, for all non-transcendental authority emerges within the impersonal and inhibiting conditions that make up molestation.

I have approached my six novelists as simultaneously instances of this dialectic and writers about it. Their sovereign control rewards a phenomenological movement of submission, even as their failures of authority-their susceptibility to molestation-solicit a critical model of suspicion. Each chapter regulates in its own fashion the ratio of trust to suspicion. Indeed, as each fictional world is composed in its own distinctive terms, so the approach varies to accommodate the specific tenor of those terms. For example, the Dickens world invites sustained attention to a wide range of relationships, all keyed to an ambiguous emotional dynamic. By contrast, the Eliot, Hardy, and Conrad novels focus more narrowly on protagonistic quests. Analysis of these latter writers is therefore briefer and more strictly attentive to the reasons why such quests are ill-conceived or foredoomed. When I reach Lawrence, I encounter a radically different kind of career from any earlier examined; my chapter attends in detail to the contours of that career in both his life and art. Career itself-the idea of disciplined progress toward an established goal-becomes a comic notion in Ulysses; thus that huge novel is approached not as a field of developing life-histories, but rather as a resonant universe, bristling at any given moment with its constituent patterns and discontinuities, but going nowhere.

The approach may vary, but, to use Lawrence's phrase, I keep my eye on carbon. The focus in every chapter remains on the identity-bearing encounter between desiring subject and restraining context. These discrete assessments are throughout related to the larger dimensions of the writer's enterprise, with increasing emphasis upon relevant connections among the six novelists. Yet this study's first allegiance is to the movement of embodied protagonists through a single writer's landscape of inhibiting conditions. Each novelist imagines this movement in his own way. I prefer to run the risk of an apparently uncentered discourse rather than force each fictional world to fit the frame 
of a univocal vocabulary (mine) and to serve as objective instances that bear out an unvarying argument (also mine).

Nietzsche and Freud remain éminences grises in this book. (Radical trust in the text's self-knowledge is as limiting a premise as radical distrust.) The contexts of molestation they clarify are, on the one hand, the imperious pressures of the body on thought and behavior, and, on the other, the increasingly disabling character of cultural scripts of identity and aspiration. As this study reaches its third phase (the Modernists), many of these molestations have themselves become auctorially assimilated. Lawrence and Joyce endow their protagonists with an awareness of the body's nature and the culture's artifice that had to enter my earlier writers' work either surreptitiously or with tragic consequences.

A more sustained focus on molestation would call even more deeply into question the authority of the subject. (Desire itself has its societal models, ${ }^{7}$ and there remain to be assessed those cultural and economic factors discussed by the Marxists.) I continue, however, to believe in a coherent subject (though neither transcendentally posited nor perfectly self-knowing), and I continue to believe it possible to approach the imaginative voice at the center of that subject's discourse. Structuralists would remind me that such approach can be conducted only through language and is therefore a chimera: language being an empty system constituted by differences and therefore hostile to qualitative notions of voice and identity. My provisional defense against this form of molestation (and against others that would wholly unseat the idea of authority) is to repeat a statement made earlier in this introduction: to be conditioned is not to be unfree; to be shaped by societal paradigms is not to be deprived of self. To the body

${ }^{7}$ For the cultural inflection of desire, see René Girard, Deceit, Desire, and the Novel: Self and Other in Literary Structure. Girard would reject my governing assumptions since he sees desire as an entirely culture-determined phenomenon: imitative, deceitful, and worthless. He assesses European novelists according to the rigor with which, in his view, they expose and excoriate desire. I find his book provocative, though it proceeds from assumptions and arrives at conclusions considerably opposed to my own. 


\section{INTRODUCTION}

and mind that we have not created ourselves must be added the language whose systemic organization is also not of our own making. Yet our freedom, like our authority, consists exactly in what we achieve with and through our conditional body, mind, and language. 